\title{
Aetio-pathology of Epistaxis: A Study of 165 Cases
}

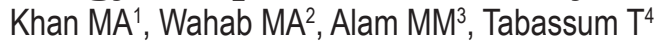

DOI: https://doi.org/10.3329/jafmc.v14i2.45898

\begin{abstract}
Introduction: Epistaxis or nose bleeding is an intensely common problem all over the world. It affects almost all age groups of people. In human life span, up to $60 \%$ of the people will experience epistaxis and only $6 \%$ of them seek medical attention.
\end{abstract}

Objectives: To find out the aetio-pathological factors of epistaxis and to observe its outcome.

Materials and Methods: This cross-sectional observational study was carried out in the Department of Otolaryngology and Head-Neck Surgery (ENT) at Combined Military Hospital (CMH), Chattogram from January 2013 to December 2016 and in CMH, Dhaka from January 2017 to July 2019 among 165 patients who reported with complaints of nose bleeding to the ENT Outpatient Department or Emergency unit of the aforementioned hospitals. The cases were diagnosed on the basis of history, clinical examination, radiological and laboratory investigations and the data regarding aetiopathological factors, outcome of the epistaxis were recorded.

Results: The study reveals that the incidence of epistaxis was $14.32 \%$ (165 of 1152 patients) with male predominance $70 \%$ with a mean age of incidence at 34.44 years. High incidence was noted in the month of December (25) and February (18) where average temperature was $25.03^{\circ} \mathrm{C}$ and average humidity $79.06 \%$ which were typical in cold weather. Low incidence was found in April (7) and October (7) where range of temperature was $26.5^{\circ} \mathrm{C}$ to $28.2^{\circ} \mathrm{C}$ and humidity $75.16 \%$ to $78.90 \%$ respectively. Majority $65.45 \%$ reported with bilateral bleeding, $75.76 \%$ reported first time, $70.90 \%$ of cases had anterior epistaxis. The commonest aetiology was trauma $40 \%$ and nasal mass was found in $7.27 \%$ cases. Majority $87.27 \%$ of patients were treated successfully by nonsurgical/non-interventional method.

Conclusion: Epistaxis is found in all age groups, mostly observed in the third and fourth decade of life with male predominance. With a proper diagnosis, prompt intervention and vigilance, epistaxis can be treated conservatively in maximum cases.

Key-words: Epistaxis, Blood dyscrasia, Blood vessels abnormality.

\section{Introduction}

Epistaxis or nose bleeding is an intensely common problem in ENT department and affects almost all age groups ${ }^{1}$. At some point in their lifetime, up to $60 \%$ of the population will experience nose bleed and $6 \%$ of these people will seek medical attention ${ }^{2}$. It is not a disease but is the result of some local or systemic disease of the body. In only a small number of cases of epistaxis can be attributed to a welldefined primary cause such as local nasal pathology, blood dyscrasia or blood vessels abnormality. In the majority, the bleeding arises from an artery or vein without any obvious abnormality to account for it; hence the term idiopathic epistaxis or spontaneous epistaxis. In idiopathic epistaxis, certain contributory factors may be implicated in the onset of bleeding; such as nose blowing, sneezing, coughing, straining, pregnancy, coryza and sinusitis. Among the local causes, trauma is the main cause of bleeding; which may result from nose pricking, physical assault. Other local causes include sinusitis, acute rhinosinusitis, atrophic rhinitis, certain granulomatous diseases (Tuberculosis, leprosy, syphilis), Osler-Rendu-Weber disease and some neoplasms (Nasopharyngeal angiofibroma, Rhinsporidiosis, Inverted papilloma, Malignant tumours). Certain systemic diseases e.g. blood dyscrasia (Leukemia, Thrombocytopenia also contribute to epistaxis. Certain drugs also contribute to epistaxis (Aspirin, Chloramphenicol, anticoagulants, alcohol).

Epistaxis may be classified according to the exit of bloodanterior epistaxis and posterior epistaxis. Anterior epistaxis is more common and less severe; occurs mainly in children and young adult and venous in origin whereas, posterior epistaxis is less common and more severe and occurs mainly in the older adult with hypertension or arteriosclerosis and arterial in origin $^{3}$. Hypertension itself cannot cause epistaxis, but there is a correlation with severity ${ }^{4,5,6}$. According to the age distribution, there is an increase in frequency from 45 to 55 years with no evidence of sex predilection? ${ }^{7}$. The incidence of epistaxis is higher the colder winter months when upper respiratory tract infection is more frequent and fluctuations in both temperature and humidity are most dramatic ${ }^{8}$. It is also more common in hot and dry climates with low humidity ${ }^{8}$. To find out the aetiopathological factors of epistaxis and to observe its outcome this study was designed.

1. Lt Col Md Ahsanuzzaman Khan, MBBS, FCPS, MCPS, DLO, Classified Specialist in Otolaryngology and Head-Neck Surgery, CMH, Dhaka (E-mail: jamanahsan166@yahoo.com) 2. Lt Col Md Abdul Wahab, MBBS, MD, Associate Professor of Biochemistry, AFMC, Dhaka 3. Lt Col Md Monsur Alam, MBBS, MCPS, DLO, FCPS, Associate Professor of Otolaryngology and Head-Neck Surgery, AFMC, Dhaka 4. Maj Taniza Tabassum, MBBS, Instructor of Forensic Medicine, AFMC, Dhaka. 


\section{Materials and Methods}

This cross-sectional observational study was carried out in the Department of Otolaryngology and Head-Neck Surgery OPD, and Emergency at Combined Military Hospital, Chattogram from January 2013 to December 2016 and in Combined Military Hospital, Dhaka January 2017 to July 2019 . A total of 165 patients with nose bleeding were purposively selected from total 1152 patients, irrespective of age, sex, professions, socio-economic and climacteric conditions. Cases were diagnosed on the basis of history, general examination, ENT examination, radiological and laboratory investigations. Patients were categorized into two groups on the basis of treatment: nonsurgical/noninterventional and surgical/interventional treatment. The data regarding the site, aetio-pathological factors, treatment and outcome of the epistaxis were recorded.

\section{Results}

Among the total 165 epistaxis cases $92.1 \%$ reported in the emergency department (Figure-1). In the present study, 116 cases $(70.3 \%)$ were males and 49 cases $(29.70 \%)$ were females with male to female ratio 2.37:1 Patient's age ranged from 3.5 to 93 years and mean age was 34.44 years. Majority $36(21.8 \%)$ were in the age group of $11-20$ years followed by $33(20 \%)$ who were in the 21-30 years (Figure-1). Month wise incidence of epistaxis cases are shown in Table-I. Bilateral nasal bleeding was in 108 (65.5\%) cases, 125 (75.8\%) had the first episode of bleeding and $117(70.9 \%)$ cases had anterior epistaxis (Table-II). Highest incidence of epistaxis was from trauma $66(40 \%)$ followed by hypertension 24 $(14.6 \%)$ (Table-III). On external examination of the nose, the nasal deformity was found in $44(26.67 \%)$ cases, which was due to facial trauma. On anterior rhinoscopy, 65(39.39\%) cases had bleeding from the septum, out of which $40(24.24 \%)$ cases from anterior part and remaining $25(15.15 \%)$ cases the bleeding was from the posterior part. In 52(31.52\%) cases, the bleeding was from the lateral wall; out of these in $33(20 \%)$ cases, it was from the inferior turbinates and $19(11.51 \%)$ cases from the middle turbinates. In $38(23.03 \%)$ cases, the bleeding was from the nasal floor and in $10(6.06 \%)$ cases the site of bleeding could not be evaluated. Mass was seen on anterior rhinoscopic examination in 12(7.27\%), which arose from septum in $7(4.24 \%$ ) cases and inferior turbinates, middle turbinates and floor in $5(3.03 \%)$ cases. Mass bleeding on touch was found in 12(7.27\%) cases. Deviated nasal septum associated with bony spur was seen in 6(3.64\%) cases. On posterior rhinoscopic examination, $7(4.24 \%)$ cases (angiofibroma-4, malignant growth-2, haemangioma-1) were seen, of which cases probing was not done.

Majority $87.27 \%$ (144) of patients were treated successfully by nonsurgical/non-interventional method. Conservative treatment strategies failed only in $12.73 \%$ (21) cases and these patients required surgical or interventional approaches. In this series, there was sinusitis in 5 cases without any mortality.

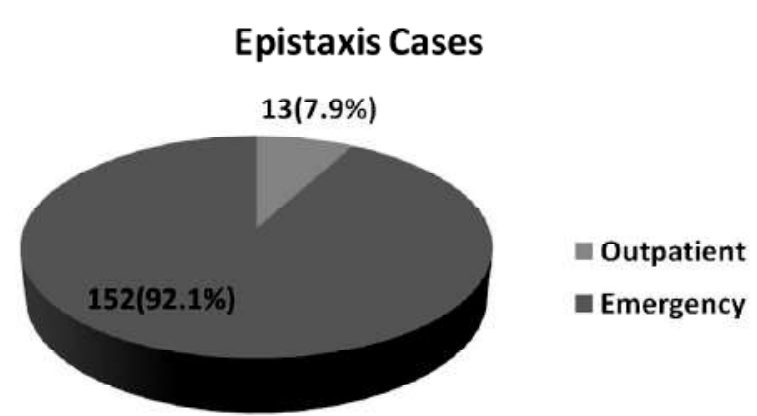

Figure-1: Presentation of epistaxis cases $(n=165)$

Table-I: Distribution of patients according to age and sex $(n=165)$

\begin{tabular}{|l|c|c|c|}
\hline \multicolumn{2}{|c|}{ Characteristics } & Number of cases & Percentage \\
\hline \multirow{4}{*}{ Age of the patients in years } & $0-10$ & 12 & 7.3 \\
\cline { 2 - 4 } & $11-20$ & 36 & 21.8 \\
\cline { 2 - 4 } & $21-30$ & 33 & 20.0 \\
\cline { 2 - 4 } & $31-40$ & 23 & 13.9 \\
\cline { 2 - 4 } & $41-50$ & 18 & 10.9 \\
\cline { 2 - 4 } & $51-60$ & 24 & 14.6 \\
\cline { 2 - 4 } Sex of the patients & $60+$ & 19 & 11.5 \\
\cline { 2 - 4 } & Male & 116 & 70.3 \\
\cline { 2 - 4 } & Female & 49 & 29.7 \\
\hline
\end{tabular}

Table-II: Seasonal incidence of epistaxis $(n=165)$

\begin{tabular}{|l|c|c|c|}
\hline Month & Cases & Average temp ${ }^{\circ} \mathrm{C}$ & Average humidity in $\%$ \\
\hline January & 9 & 20.1 & 80.0 \\
\hline February & 18 & 24.3 & 81.1 \\
\hline March & 16 & 27.0 & 60.7 \\
\hline April & 7 & 26.5 & 75.2 \\
\hline May & 13 & 27.7 & 80.0 \\
\hline June & 16 & 27.5 & 86.9 \\
\hline July & 21 & 29.6 & 80.3 \\
\hline August & 13 & 29.4 & 83.9 \\
\hline September & 11 & 28.8 & 93.1 \\
\hline October & 7 & 28.2 & 78.9 \\
\hline November & 9 & 24.6 & 77.8 \\
\hline December & 25 & 21.2 & 75.9 \\
\hline
\end{tabular}

Table-III: Types of epistaxis $(n=165)$

\begin{tabular}{|l|l|r|c|}
\hline Characteristics & \multicolumn{1}{|c|}{ Type } & Number & Percentage \\
\hline \multirow{2}{*}{ Nasal bleeding } & Bilateral & 108 & 65.5 \\
\cline { 2 - 4 } & Unilateral & 57 & 34.6 \\
\hline \multirow{2}{*}{ Occurrence } & First time & 125 & 75.8 \\
\cline { 2 - 4 } & Recurrent & 40 & 24.2 \\
\hline \multirow{2}{*}{ Type of epistaxis } & Anterior & 117 & 70.9 \\
\cline { 2 - 4 } & Posterior & 18 & 10.9 \\
\cline { 2 - 4 } & Both & 30 & 18.2 \\
\hline
\end{tabular}

Table-IV: Distribution of cases according to aetiology $(n=165)$

\begin{tabular}{|l|c|c|}
\hline \multicolumn{1}{|c|}{ Causes of Epistaxis } & Cases & Percentage \\
\hline Trauma & 66 & 40.0 \\
\hline Associated with Hypertension & 24 & 14.6 \\
\hline Idiopathic & 23 & 13.9 \\
\hline Ulceration & 13 & 7.9 \\
\hline Blood dyscrasia & 10 & 6.1 \\
\hline Rhinosporidiosis & 7 & 4.2 \\
\hline DNS \& Septal spur & 6 & 3.6 \\
\hline Angiofibroma & 4 & 2.4 \\
\hline Atrophic rhinitis & 4 & 2.4 \\
\hline Others & 9 & 5.5 \\
\hline Total & 165 & 100 \\
\hline
\end{tabular}




\section{Discussion}

Epistaxis is a reasonably common symptom encountered in this otolaryngological experience. This study suggests the fact that epistaxis is essentially a problem of the younger population and trauma apparently plays a considerable role as a causative factor. This study demonstrated that patients with epistaxis are more common in younger than 40 years $(104,63.03 \%)$, with a mean age of 34.44 years, which differ from Varshney S et $a^{2}$. Men (116, 70.30\%) were affected more frequently than female $(49,29.70 \%)$ by almost $2.37: 1$ which is in accordance with the study by Varshney $S$ et al ${ }^{2}$. The number of epistaxis cases was higher in the reported hospitals during a cold climate when the average temperature was $25.03^{\circ} \mathrm{C}$ and average humidity was $79.06 \%$, and also during hot and dry climate when the average temperature was $\left(27.0^{\circ} \mathrm{C}\right)$ and average humidity was lowest $(60.74 \%)$ (Table-II). This finding is consistent with the finding of previous study ${ }^{8}$. Epistaxis is more prevalent in dry climates and during cold weather due to the dehumidification of the nasal mucosa which leads to mucosal irritation ${ }^{8,9}$. According to a study by Bray $D$ et al, there is no relationship between epistaxis and temperature or seasonal variation which contradicts the previous view that incidence of epistaxis displays seasonality ${ }^{10}$.

The exact cause of increased incidence of epistaxis in male is not known, but it may be due to more exposure to agricultural works, travelling, social activity etc. This study support that, trauma (accidental injury, physical assault-66 cases, 40\%) plays a major role in epistaxis. In Bangladesh, more than seventy per cent population ${ }^{11}$ is related to agricultural activity and during the season of harvesting traumatic epistaxis might become higher. Except with severe facial trauma, such as motor vehicle accidents, this epistaxis is usually from an anterior nasal source and easily treated ${ }^{12}$ and associated with nasal deformity/fracture nasal bone. The second most group of epistaxis patient $(24,14.55 \%)$ has associated cardiovascular disease (Hypertension) but, it is uncertain whether cardiovascular factor (Hypertension) constitutes the sole cause of epistaxis or not. In such cases, the amount of bleeding is mild, intermittent, posterior and maximum cases site of bleeding cannot be located. Shaheen was unable to find any difference in the distribution of blood pressure in subjects suffering from epistaxis, from that of a control group who were not bleeding disorder ${ }^{3}$. Furthermore, he points out that the relationship of arterial muscle degeneration to epistaxis is presented in the persistence rather than the initiation of bleeding because of the arteries with a defective muscle layer loss power to contraction. He also points out that the causative factor in the initiation of bleeding, still unknown, may be responsible for the mechanism of rupture of the vessel. The third most cases of epistaxis are idiopathic $(23,13.94 \%)$ which is much lower than Varshney S (35.23\%)2.

Every case of epistaxis should be thoroughly examined and a possible haemorrhagic diathesis should be excluded as soon as possible. The patient should be carefully questioned about recent trauma to the nose and about the previous use of drugs for his diseases. Posterior packing of the nose should not be carried out without urgent reason, because it causes serious discomfort to the patient and may also cause serious complications, even in the antibiotic era ${ }^{13,14}$.

Federspi ${ }^{15}$ points out that, arterial ligation does not imply a greater risk than protracted and severe bleeding. He opined that arterial ligation should be considered instead of renewed packing if the bleeding could not be arrested with conservative measures within 3 or 4 days. Before carrying out an arterial ligation, the source of bleeding should be ascertained as exactly as possible with reference to its relation to the middle turbinate. In traumatic epistaxis and in cases where the bleeding apparently comes from above the middle turbinate, the ethmoidal arteries should be occluded in the first place. In this study, arterial ligation was not required. If the patient has recently suffered from skull trauma, and in all cases of very profuse bleeding, the possibility of an aneurysm of an internal carotid artery should be kept in mind and angiography should be carried out. The same applies to patients with Maurer's triads: blindness in one eye, signs of orbital fracture and profuse nasal bleeding ${ }^{16}$. The failure rate of $10-14 \%$ has been reported with arterial ligation, and mainly it is because of the inappropriate selection of the vessel. The rich vascular network of the nasal mucosa allows for a new form distribution after ligation of the vessel and this may maintain the haemorrhage, leading to multiple unsuccessful vascular ligations ${ }^{17}$.

Selection of adequate treatment with severe epistaxis should be considered by three parameters: efficiency, complications and cost-benefit. Nasal packing has the advantages and its efficiency is closer to $48 \%{ }^{18}$. This study demonstrated that $87.27 \%$ (144 cases) of patients were treated successfully by nonsurgical/non-interventional method. Conservative treatment strategies failed only in $12.73 \%$ (21) cases and these patients required surgical or interventional approaches.

Many complications have been reported in relation to packing: septal haematoma and abscess from traumatic packing, pressure necrosis secondary to excessively tight packing, neurogenic syncope during packing, hypoxia, cardiac arrhythmia, myocardial ischemia and gram-negative sepsis. Other relative minor complications such as eustachian tube dysfunction, sinusitis, facial oedema and septal perforation. Because of the possibility of the toxic shock syndrome with prolonged nasal packing, use of a topical anti-staphylococcal antibiotic ointment on the packing materials has been recommended ${ }^{19,20}$. In this series, there was sinusitis in 5 cases without any mortality. Cryotherapy is helpful only in cases of anterior epistaxis ${ }^{21}$. However, some important complications have been reported: amaurosis, bacteraemia, hypoxia, $\mathrm{CO}_{2}$ poisoning and death (Hicks and Norris, 1989). Laser $^{22}$ can also be applied for treatment of epistaxis. Only $9.09 \%$ (15 cases) required blood transfusion, which is closer to the reported study ${ }^{17}$. 


\section{Conclusion}

Epistaxis cases are mostly reported to the hospital as an emergency cases and most of them were in third and fourth decade of life with male predominance. Incidence was higher in low temperature with high humidity and dry climate. Trauma was the most common cause of epistaxis and were treated successfully by non-interventional method.

\section{References}

1. Shaheen $\mathrm{OH}$. Epistaxis in: Scott Browns Otolaryngology. 5th ed, Vol-4, edited by IS Mackay and TR Bulh.

2. Varshney S, Saxena RK. Epistaxis: A retrospective clinical study. Indian Journal of Otolaryngology and Head and Neck Surgery 2005; 57(2):125.

3. Shaheen $\mathrm{OH}$. Epistaxis in the middle-aged and elderly (Doctoral dissertation, University of London).

4. Kikidis D, Tsioufis K, Papanikolaou V et al. Is epistaxis associated with arterial hypertension? A systematic review of the literature. European Archives of Oto-Rhino-Laryngology 2014; 271(2):237-43.

5. Petruson B, Rudin R, Svärdsudd K. Is high blood pressure an aetiological factor in epistaxis? ORL 1977; 39(3):155-60.

6. Min HJ, Kang H, Choi GJ et al. Association between hypertension and epistaxis: systematic review and meta-analysis. Otolaryngology-Head and Neck Surgery 2017; 157(6):921-7.

7. Padgham N. Epistaxis: anatomical and clinical correlates. The Journal of Laryngology \& Otology 1990; 104(4):308-11.

8. Nunez DA, McClymont LG, Evans RA. Epistaxis: A study of the relationship with weather. Clinical Otolaryngology \& Allied Sciences 1990; 15(1):49-51.

9. Medscapecom. Epistaxis. [Online]. Available from: https:// emedicine.medscape.com/article/863220-overview\#a5 [Accessed 23 August 2019]

10. Bray D, Giddings CE, Monnery P, Eze N, Lo S, Toma AG. Epistaxis: Are temperature and seasonal variations true factors in incidence?. The Journal of Laryngology \& Otology 2005; 119(9):724-6.
11. World Bank. (2019). Bangladesh: Growing the Economy through Advances in Agriculture. [online] Available at: https://www.worldbank. org/en/results/2016/10/07/bangladesh-growing-economy-throughadvances-in-agriculture [Accessed 27 Aug. 2019].

12. Hara HJ. Severe epistaxis. Archives of Otolaryngology 1962; 75(3):258-69.

13. Kuhn AJ, Hallberg OE. Ligation of both external carotid arteries for control of epistaxis. AMA Archives of Otolaryngology 1955; 62(2):130-3.

14. King JT. Nasal necrosis associated with postnasal packing for protracted epistaxis. The Laryngoscope 1960; 70(2):194-5.

15. Federspil P. Blood vessel ligations in uncontrollable epistaxis. HNO 1971; 19(6):171-5.

16. Maurer JJ, Mills M, German WJ. Triad of unilateral blindness, orbital fractures and massive epistaxis after head injury. Journal of Neurosurgery 1961; 18(6):837-40.

17. Hicks JN, Norms JW. Office treatment by cryotherapy for severe posterior nasal epistaxis... update. The Laryngoscope 1983; 93(7):876-9.

18. Monux A, Tomas M, Kaiser C, Gavilan J. Conservative management of epistaxis. The Journal of Laryngology \& Otology. 1990; 104(11):868-70.

19. Smith JA. Nasal emergencies and sinusitis. Emergency Medicine: A Comprehensive Study Guide. 4th ed. New York, NY: McGraw-Hill Publishing 1996:1087-91.

20. Frazee TA, Hauser MS. Nonsurgical management of epistaxis. Journal of Oral and Maxillofacial Surgery 2000; 58(4):419-24.

21. Varshney S. Treatment of Anterior epistaxis by Cryosurgery. J IMAAcad UP Chapter (JAMS) 1995; 8:136-9.

22. Dixon JA, Parlein JL. Laser photocoagulation in HHT. Otolaryngol Head Neck Surg 1981; 89:204. 